\title{
A Comprehensive Review of Synthesis, Applications and Future Prospects for Silica Nanoparticles (SNPs)
}

\author{
Faheem Akhter ${ }^{1}$. Ahsan Atta Rao ${ }^{1} \cdot$ Mahmood Nabi Abbasi $^{1} \cdot$ Shafeeque Ahmed Wahocho ${ }^{1} \cdot$ Mukhtiar Ali Mallah $^{1}$. \\ Hafiz Anees-ur-Rehman ${ }^{1} \cdot$ Zubair Ahmed Chandio $^{1}$
}

Received: 7 August 2021 / Accepted: 11 December 2021 / Published online: 5 January 2022

(c) The Author(s), under exclusive licence to Springer Nature B.V. 2022

\begin{abstract}
Silica nanoparticles (SNPs) have shown great applicability potential in a number of fields like chemical, biomedical, biotechnology, agriculture, environmental remediation and even wastewater purification. With remarkably instinctive properties like mesoporous structure, high surface area, tunable pore size/diameter, biocompatibility, modifiability and polymeric hybridizability, the SNPs are growing in their applicable potential even further. These particles are shown to be non-toxic in nature, hence safe to be used in biomedical research. Moreover, the molecular mobilizability onto the internal and external surface of the particles makes them excellent carriers for biotic and non-biotic compounds. In this respect, the present study comprehensively reviews the most important and recent applications of SNPs in a number of fields along with synthetic approaches. Moreover, despite versatile contributions, the applicable potential of SNPs is still a tip of the iceberg waiting to be exploited more, hence, the last section of the review presents the future prospects containing only few of the many gaps/ research extensions regarding SNPs that need to be addressed in future work.
\end{abstract}

Keywords Silica nanoparticles $\cdot$ Mesoporous $\cdot$ Nanotechnology $\cdot$ Nanostructure

\section{Introduction}

Nanotechnology deals with development of unique nanoscale particles. These particles have found revolutionizing applications in various industries like electronics,

Faheem Akhter

faheemakhtar86@quest.edu.pk

Ahsan Atta Rao

ahsanatta786@gmail.com

Mahmood Nabi Abbasi

mahmoodabbasi73@gmail.com

Shafeeque Ahmed Wahocho

shafique79@gmail.com

Mukhtiar Ali Mallah

mukhtiar085@gmail.com

Hafiz Anees-ur-Rehman

aneesrehman43@gmail.com

Zubair Ahmed Chandio

zubairchandio@quest.edu.pk

1 Department of Chemical Engineering, Quaid-e-Awam

University of Engineering, Science \& Technology,

Nawabshah, Pakistan medicine and consumer products. In recent years, one such example of nanotechnology are silica nanoparticles that have found a widespread use in industrial, food and agricultural fields. Generally, the nanoparticles are synthesized via physical and chemical methods. The physical methods include ultrasonic shot peeling, severe plastic deformation, gas condensation, high energy ball milling and pyrolysis [1]. These techniques usually are employed to synthesize metallic nanoparticles. On the other hand, Chemical methods include electrochemical procedures, reduction of chemicals/ phytochemicals, chemical coprecipitation, chemical vapor condensation and pulse electrodeposition [2-4]. In comparison, the chemical methods involve the use of various toxic and hazardous chemicals that are harmful for the biosphere and environment. This paved the way for the development of green nanotechnology that uses environment friendly methods and bio-agents to synthesize nanoparticles. In general, the green nanotechnology uses microorganism (fungi, bacteria, algae) and nature derived substrates (plant extracts) to synthesize nanoparticles. Besides being eco-friendly, these methods are comparably inexpensive too $[4,5]$. Silica nanoparticles are usually synthesized from alcohol solution of silicon alkoxides. Ammonia is used as a catalyst and the 
nanoparticles can range from $50 \mathrm{~nm}-1 \mu \mathrm{m}$, depending upon the versatile applications.

Metal oxides play a significant role in many areas of nano-material science. In any material, the particle size determines its structure, size and other properties that are affected by the size of oxide particles. For example, the chemical reactivity and conductivity of metal oxide are significantly influenced by the size of an oxide particle $[6,7]$. Similarly, the surface properties are equally important due to their huge role during solid-liquid or solid-gas reactions [8]. Numerous metal nano-particles have been synthesized such as $\mathrm{ZrO}_{2}, \mathrm{CeO}_{2}, \mathrm{TiO}, \mathrm{TiO}_{2}$ etc. which can be exploited for applications such as sensors, coatings, agrochemicals, anti-corrosives, fuel cells and catalysts [9, 10]. For example, the NPs of iron oxide carry a strong magnetic characteristics, hence are used for the relevant applications such as separation of cells parts, drug delivery, nano-coating and food packaging [11-13].

Silica is one of the most abundant materials on earth [14]. Silica nanoparticles (SNPs) have gravitated much of the recognition by the research world due to their diverse physiochemical properties [15]. Based on the pore size, these particles can be divided into mesoporous and nanoporous [16]. The size of the particles can be varied by altering the surfactants' composition during synthesis [17]. Silica nanoparticles (SNPs) are usually inexpensive to produce on a large scale, are hydrophobic with good surface area, pore volume and biocompatibility, hence they have found wide variety of applications. For example, due to their non-toxic nature and fantastic adsorption capacity, the silica nanoparticles (SNPs) have been employed for drug delivery [18, 19]. Recently, the researchers have successfully utilized the silica nanoparticles (SNPs) as loading multifarious for cargo ranging from drugs to macromolecules, such as RNA, DNA and proteins $[20,21]$. So far, the silica nanoparticles have found applications in numerous directions of research such as biomedicine, biotechnology, drug delivery, food, personal care products, pesticides, adsorption, semiconductors and ceramics [22]. More recently, the silica nanoparticles have been employed to adsorb the oil spillage during oil exploration, transportation and storage $[23,24]$. The research is still in the progress to explore and exploit more possible applications of silica nanoparticles [22].

\section{Synthesis of Silica Nanoparticles (SNPs)}

\subsection{Synthesis of SNPs (Chemical Methods)}

In the past, silica nanoparticles were synthesized using classical methods like sol-gel method, stober's method, flame synthesis and micro emulsion [17]. These chemical routes are easy to follow and modify in terms of parameters but can be costly and difficult to manage. For example, during reverse micro emulsion, the surfactant molecules are dissolved in the presence of water which produce the spherical miscelles. Although this procedure is effective, yet it is costly and difficult to segregate the surfactants in the final products [16]. Nevertheless, the nanoparticles synthesized via this route were successfully used as coating to attach functional groups [25, 26].

Another popular route to synthesize silica nanoparticles is chemical vapour condensation (CVC) [27]. During this method, silicon tetrachloride is reacted with oxygen and hydrogen. The physical aspects of the nanoparticles such as morphology and particle size can be controlled to the desired characteristics in this process. This method is widely used to produce nanoparticles in powder form [28-30]. Similarly, the sol-gel method is a well known technique used widely to synthesize silica and silica gel $[31,32]$. It mainly involves the hydrolysis and condensation of metal alkoxides like TEOS or inorganic salts like sodium silicate in the presence of a catalyst. The catalyst being acid or base [33, 34]. When forming silica particles using metal alkoxides (TEOS, TMOS), the hydrolysis gives silanol groups that polymerize to form into silica structure. Another method called stober's method was first experimented and proposed by Werner Stober. Using ammonia as a catalyst, he successfully synthesized spherical silica particles from silica alkoxide alcohol solution. The particle size ranged from 5 to $2000 \mathrm{~nm}$ [35]. This method has evolved with time and made much more efficient and versatile in terms of controlling parameters and acquiring the desired properties [36, 37]. Usually, the acid catalyzed systems produce gel structure whereas the Stober's method gives monodispersed silica particles [35]. Despite its own advantages, the chemical synthesis methods are expensive, involve toxic substances and require high energy, which necessitated the birth of biogenic routes [22]. Figure 1 schematically represents the most commonly used chemical techniques to synthesize silica nanoparticles.

\subsection{Synthesis of SNPs (Biogenic Methods)}

The biogenic methods of synthesizing silica nanoparticles involve using microorganisms and nature derived substrates, such as bacteria, fungi, algae and plant extracts/metabolites [38]. For example, the biosilicification process produces silica via silicatein and silaffin, which has led to the designing of synthetic cationic polypeptides. Moreover, the usability of fungus for silica synthesis had been investigated by many researchers. For example, the fungus Fusarium oxysporum was reacted with aqueous anionic complex at room temperature to form silica [39, 40]. Recently, various biomass have been investigated to synthesize silica nanoparticles, like rice husk, sugarcane bagasse and rice straw [14, 41-44]. Silica present in the biomass is initially isolated and formed into 
Figure 1 Common Chemical Synthesis Technique for Silica Nanoparticles. Reused with permission from Ref. [26]

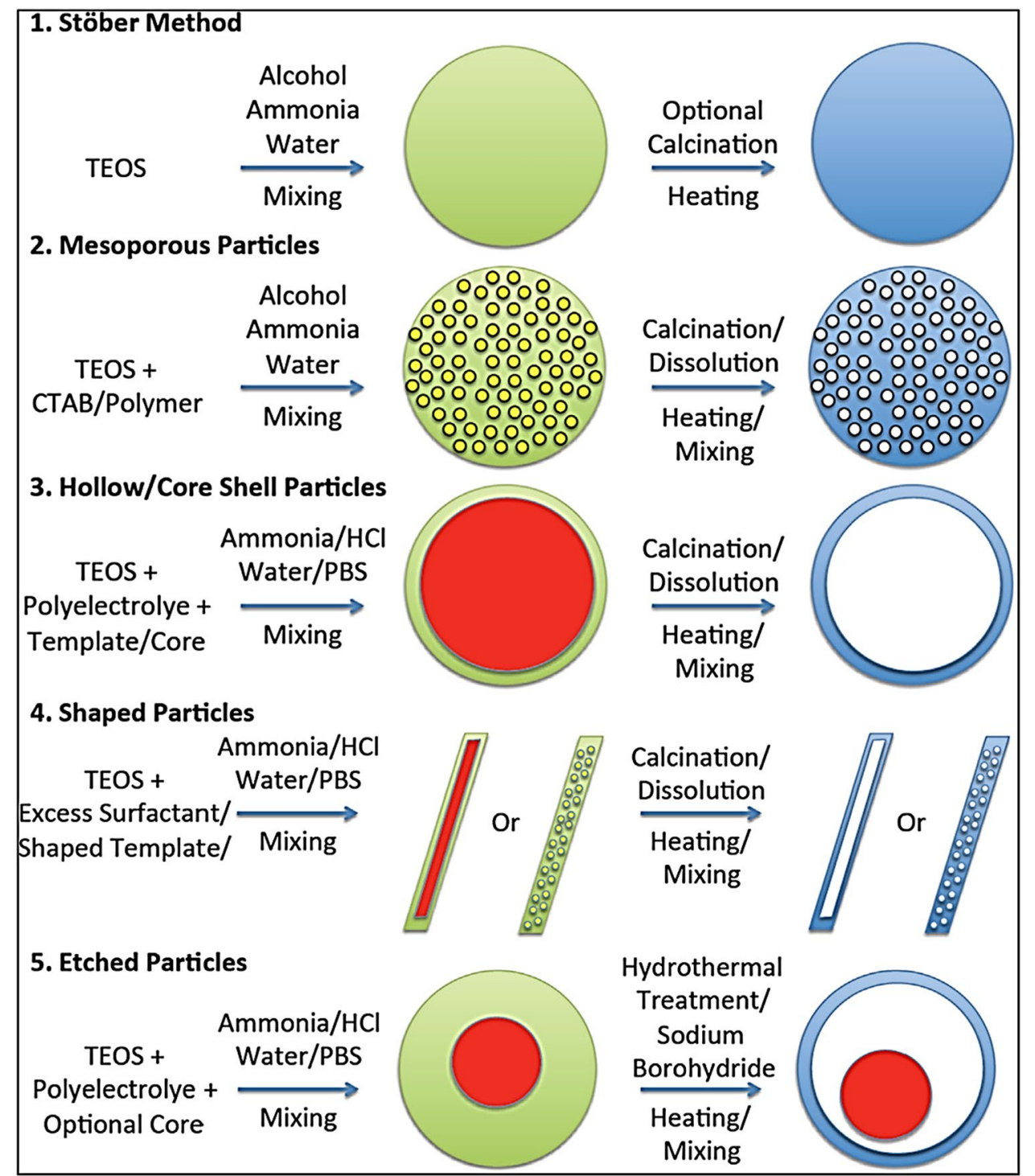

sodium silicate solution [45]. Number of parameters affecting the process that need to be optimized like temperature, $\mathrm{pH}$ and time [46]. Such a step is an appreciative way to deal with the biomass and convert it into valuable products like silica nanoparticles that are gaining wider applications with time [47].

In order to synthesize silica, the biomass is usually washed with distilled water to remove adhering impurities followed by treatment with leaching agents [48]. The leaching treatment is aimed to remove the metallic impurities contained by the biomass [49]. Table 1 shows the most common metallic impurities in rice husk and their removal via different acids. If not removed, these metallic impurities can downgrade the physiochemical properties of the obtained silica particles [41]. In this regard, 3 acids are most commonly used; hydrochloric acid, nitirc acid and sulfuric acid. Among them, the $\mathrm{HCl}$ is known to
Table 1 Metallic Impurities in Rice Husk and its leaching with different acids. Open Access ref. [55]

\begin{tabular}{lclc}
\hline Constituent (\%) & $\begin{array}{l}\text { Non-Leached Rice } \\
\text { Husk Ash at } 600{ }^{\circ} \mathrm{C}\end{array}$ & $\begin{array}{l}\text { Acid Leached Rice Husk } \\
\text { Ash at } 600{ }^{\circ} \mathrm{C}\end{array}$ \\
\cline { 3 - 4 } & & $\begin{array}{l}\text { Hydro- } \\
\text { chloric } \\
\text { Acid }\end{array}$ & Sulfuric Acid \\
& \multicolumn{3}{c}{} \\
\hline $\mathrm{SiO}_{2}$ & 95.77 & 99.58 & 99.28 \\
$\mathrm{Al}_{2} \mathrm{O}_{3}$ & 0.05 & 0.02 & 0.61 \\
$\mathrm{FeO}_{3}$ & 0.05 & 0.03 & 0.02 \\
$\mathrm{CaO}$ & 0.67 & 0.04 & 0.05 \\
$\mathrm{MgO}_{\mathrm{Cl}}$ & 0.40 & 0.02 & 0.04 \\
$\mathrm{SO}_{3}$ & 0.02 & 0.02 & 0.01 \\
$\mathrm{~K}_{2} \mathrm{O}_{2}$ & 0.62 & 0.02 & 0.05 \\
$\mathrm{Na}_{2} \mathrm{O}$ & 0.62 & 0.02 & 0.02 \\
$\mathrm{P}_{2} \mathrm{O}_{5}$ & 1.26 & - & - \\
\hline & 0.46 & 0.11 & 0.13 \\
\hline
\end{tabular}


remove $99 \%$ of the metallic impurities [49-53]. Base and salt treatment is also investigated to remove the impurities, such as sodium hydroxide and $\mathrm{KMnO}_{4}$ [54].

This leaching pre-treatment is followed by calcination of biomass. Synthesis of high purity silica highly depends on temperature, time and air/oxygen flow [56]. For example, in case of rice husk, the silica obtained at 600 degrees was amorphous in nature while at 700 was both amorphous and crystalline. Higher temperature than 700 is shown to produce more crystalline structure of rice husk than amorphous [57-60].

Various researchers used green synthesis route to obtain amorphous silica nanoparticles (SNPs) using rice husk and sugar beet bagasse [22]. The researchers who used rice husk successfully obtained semi-crystalline porous silica nanoparticles and silica nanoparticles [29, 61]. On the other hand, the researchers who used sugar beet bagasse also synthesized silica nanoparticles [62]. Figure 2 shows the classified chemical and biogenic routes to synthesize silica nanoparticles (SNPs).

\section{Applications of Silica Nanoparticles (SNPs)}

\subsection{Chemical Applications of SNPs}

Silica nanoparticles possess specific sites that make it easy for the particles to get functionalized. For example, the mesoporous silica nanoparticles (MSNs) contains 3 major sites for functionalization; pore walls, pore entrance and interior/exterior of the particle surface [16, 63]. Figure 3 shows the mechanism for MSNs formation.

Silica particles are usually functionalized via co-condensation or post synthesis grafting using organo-substituted trialkoxysilanes [17]. When functionalized on to the pore walls, the mesopores do not get blocked by non-siliceous group. During functionalization, the alkoxysilanes bind to the surface silanol groups. Similarly, numerous metals have also been functionalized onto the mesoporous silica particles $[65,66]$. For example, Aluminum is one of the most common metals functionalized on to MSNs for catalytic related applications. In this regard, Zhai et al. [67] synthesized aluminosilicate nanoparticles. Moreover, the particles were mesoporous and the particle size was limited to 20 $\mathrm{nm}$ by using polyethylene glycol. Similarly, Zhao et al. [68] synthesized magnetic MSNs using hermatite nanocore. The
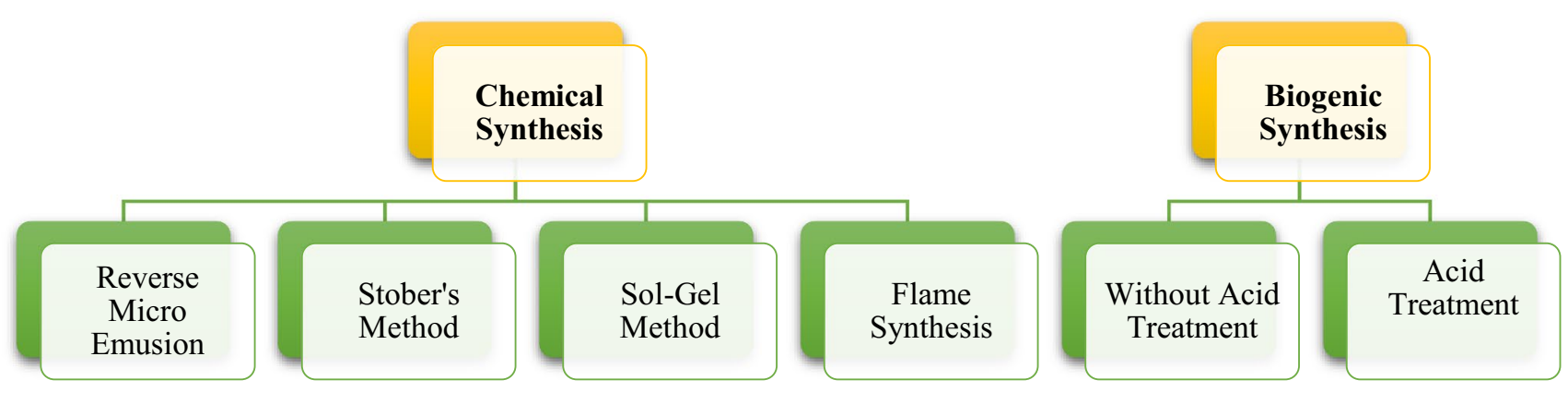

Figure 2 Chemical and Biogenic routes to synthesize silica Nanoparticles
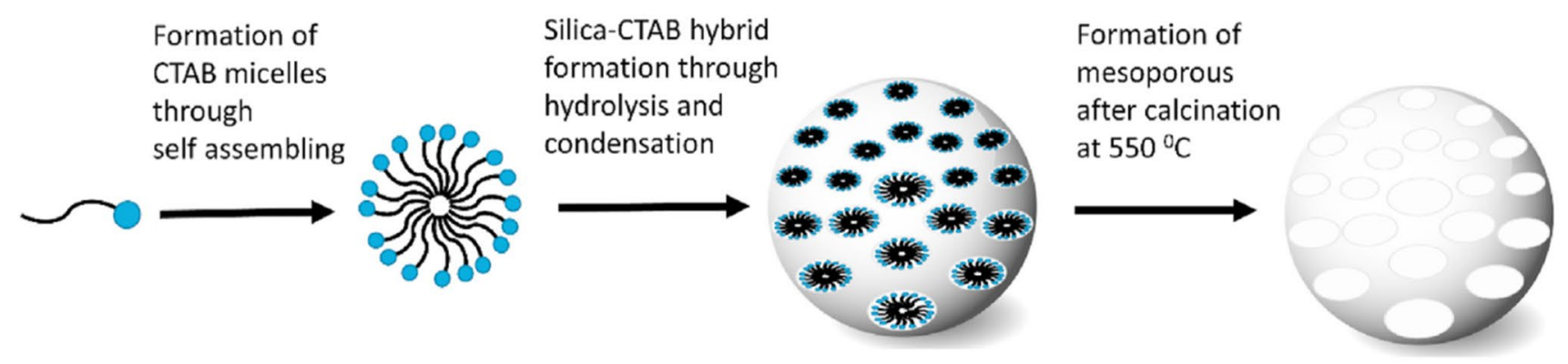

\section{CTAB monomer}

Figure 3 Formation Mechanism of Mesoporous Silica Nanoparticles (MSNs). Open Access Ref. [64] 
particles were used for drug delivery of ibuprofen. Huang et al. [69] used magnetic nanoparticles and quantum dots (CdSe/ZnS) to synthesize MSNs. Likewise, Soyoko et al. [70] synthesized MSNs embedded with titanium oxide and iron oxide. The prepared material was used for catalytic reactions. More recently, Sandra et al. [71] synthesized silica based silver nanoparticles to be used as antimycobacterial agents against Mycobacterium tuberculosis. Similarly, Diogo et al. [72] used silver, copper and copper hydroxy salt to synthesize the respective metallic silica nanoparticles, which showed promising and satisfactory results when used as antibacterial agents. One of the advantageous features of using MSNs is that their inner as well as outer surfaces can be immobilized. In this regard, Lin et al. [73] successfully immobilized fluorophore on to the inner surface, whereas grew dense polymer onto the external surface of MSNs to be used for the detection of neurotransmitters. Likewise, the more recent development was seen by Maurel et al. [74] who developed hybrid silylated fluorophore in the core of SNPs and observed its efficiency against tumor-cell-targeting.

It has been shown to use various MSNs, each immobilized with a different compound in a single-pot catalytic reaction. Usually, such types of MSNs are chemically incompatible and yet shown to participate without neutralizing each other. This was demonstrated by Huang et al. [69] where 4-nitrobenzaldehyder methyl acetal converted to aldehyde in the presence of 2 different immobilized species of MSNs. A remarkable yield of $97.7 \%$ was achieved. Similarly, Zaharudin et al. [75] demonstrated the controlled load and release of molecules on to the pore entrance of MSNs. This could contribute to drug delivery applications [76].

\subsection{Biomedical \& Biotechnological Applications of SNPs}

When it comes to biomedical, the research of drug delivery carries one of the highlighting importance. Using the engineered nanostructures for the targeted delivery of drugs in the patient's body is a significantly recognized feature under research [76]. These nanostructures can act as carriers and target specific organs or tissues in the body. In this regard, MSNs have achieved significant recognition due to their high surface area and porous structure. These particles have been used as nano-carriers for drug delivery in recent times [18, 20, 22, 77-79]. Aughenbaugh et al. [80] investigated the release of drug using silica xerogels as potential carriers. Moreover, the hydrophobicity of the drugs reduces their absorption during oral dose. This is improved by using SNPs as carriers for such hydrophobic drugs and shown promising results during oral doses [76]. It is possible due to the negative charge on the surface of silica nanoparticles whereas positive on hydrophobic drug [28]. Furthermore, what makes these nanoparticles so efficient are their loading capacity, biocompatibility and possible functional group modification [16]. In this, Zhang et al. [81] used SNPs as carriers for hydrophobic drug telmisartan. The SNPs were shown to improve the drug permeability. Likewise, Samira et al. [82] and Nihal et al. [83] showed a significant improvement in the functionality of curcumin (anticancer drug) conjugated with SNPs than used alone. Lein et al. [84] synthesized nanoparticles for controlled drug delivery by successfully grafting magnetic and thermosensitive nanoparticles onto the surface of $\mathrm{Fe}_{3} \mathrm{O}_{4}$ coated silica particles. Similarly, the surface modified SNPs have been investigated for boron neutron capture [85-89].

Having large surface area and small size, the SNPs have found their applicability as biomarkers to detect specific biomolecules. In this regard, the use of Quantum Dots (QD) is widespread, however their insolubility in water and toxicity caused by heavy metals have provoked researchers to find alternate substitutes. In this respect, various researchers covalently linked the compounds; such as fluorophores and tetramethyl rhodamine isothiocyanate dye, onto the silica nanoparticles. The fabricated materials showed water soluble and less/non-toxic conduct with promising results, hence a worthy substitute for QDs [90-94]. Moreover, the adhesive properties of SNPs have been utilized by researchers to synthesize glue like material, which is shown to be less invasive compared to commonly used tissue adhesives like cyanoacrylate [22]. Another remarkable property owned by SNPs is their differentiation of cells, which has been proposed as a treatment for obesity $[19,95]$. Flourine Nucleus (19F) is very sensitive and present in traces of biological tissues, hence used to detect even the very minute details. However, it is challenging to develop fluorine containing probes for 19F MRI. This scenario has led to the grafting of fluorine onto the silica nanoparticles, which can be immobilized on the inner as well as outer layers of the particles [96-99].

Medical diagnosis and research have to interact and detect very minute targets like proteins, enzymes, DNA and mRNA, hence requiring a very precise and specific detection. In this respect, the nanotechnological developments are showing to be a supportive and contributive factor in medical research [100]. Nanotechnology has already shown promising results in drug delivery, diagnosis, medical imaging, cancer treatment, diabetes treatment and more $[19,61,79]$. SNPs have shown to be good adsorption and immobilization medium for quinizarin diester [101]. Maleki et al. [102] developed drug delivery system using silica nanoparticles. They further showed the possible feasibility of using the same system for entrapment of colorless water soluble drugs like isoniazid. Following the same track, various researchers in recent time have explored more water soluble drugs that were successfully immobilized onto the silica nanoparticles and used for drug delivery [103-107]. For example, Marzieh et al. [108] developed silica based nanocarriers for the target 
delivery of doxorubicin drug to breast cancer cells (4T1). The nanocarriers were fabricated with quantum dots (QD) coating on MSNs followed by amine functionalization of silica surface. The drug was into the silica pores and biheterofunctional PEG was covalently bound to the surface of core-shell QDMSNs. The results were remarkably positive. Figure 4 shows the SEM images of the synthesized nanoparticles (QDMSNs, PEG QDMSNs, HRTEM and QDNPs).

Antibiotics have been a major development of medical research. However, these drugs come with its own challenges like depletion of their antibacterial effect with time and release of toxic substances into the environment [71]. On the contrary, various compounds have been synthesized as antibacterial agents that kill bacteria on contact, such as quaternary ammonium compound [109]. These antibacterial agents have been cross-linked to SNPs to develop particles with chemically inert nature, tranparent and good mechanical properties $[6,110]$. One of the issues related to development of latest antibiotics are their toxicity and low bacterial penetration. To address these issues, SNPs were used to encapsulate peptide, which showed to be effective in treating lung infection (Pseudomonas aeruginosa). The SNPs being biodegradable, ensured target release of peptide [111]. Similarly, the treatment of diseases like tuberculosis carries its own set of challenges that need to be overcome. For example, well known drug called clofazimine is shown to have poor solubility and adsorption in GI tract. To overcome this, the researchers [112] encapsulated this drug onto SNPs, thus resulting in its enhanced stability and solubility. In short, the SNPs can be a reliable support for immobilization and encapsulation of antibacterial agents/drugs in future with minimum/less toxicity [18, 53].

\subsection{Agricultural Applications of SNPs}

Higher agricultural production ensures the survival of the growing population in the world. Unfortunately, microbial and insect attacks can significantly reduce this yield. This issue is being resolved by using pesticides but their health and environmental concerns have led to even worse problems. The excessive use of pesticides is not only harmful for the soil, but also for human health and environment. The direct shower of pesticides onto the crops might get absorbed and become intact within the crops, consequently, ending up in the human bodies and giving way to numerous diseases like respiratory symptoms, neurological problems, hormonal, reproductive abnormalities and even cancer [113]. This has provoked the researchers to synthesize an eco-friendly insecticides. Furthermore, another approach to do away with the pesticides is to strengthen the immunity of seeds against microbial attacks. This has been possible using MSNs [114, 115]. For example, Torney et al. [116]
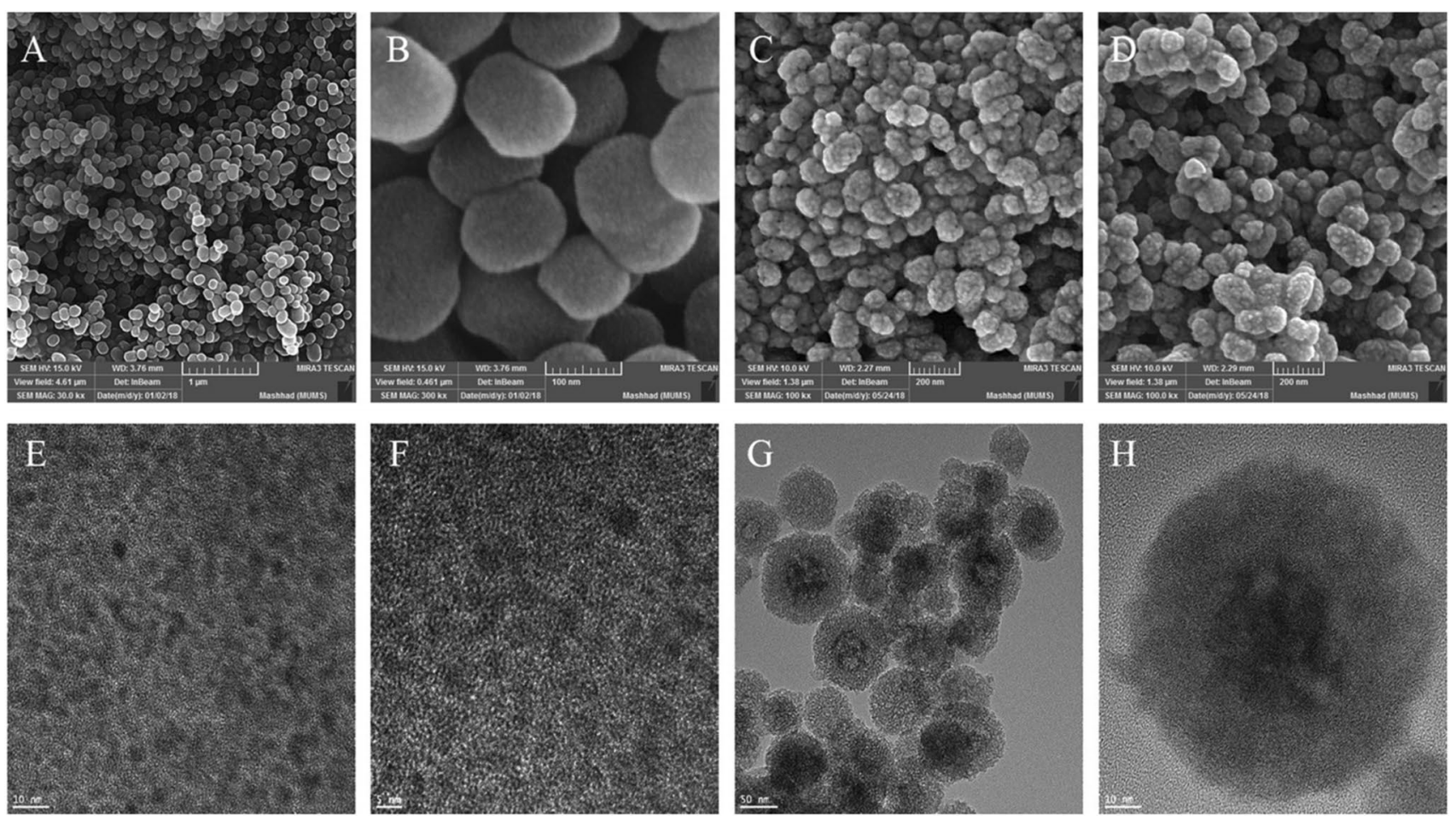

Figure 4 SEM Images of QD Mesoporous silica NPs (A, B), PEGylated QD Mesoporous silica NPs (C, D), HRTEM micrograph (E, F) and QD NPs $(G, H)$. Open Access ref. [108] 
loaded MSNs with genetic material and chemical inducer to be successfully carried into intact leaves and plant cells of maize seeds. This pre-treatment of maize seeds with silica nanoparticles resulted in maize seeds with antifungal resistance, higher nutritional content and greater germination rate. Similarly, Siddiqui et al. [117] were able to achieve $22.16 \%$ higher germination rate by using $8 \mathrm{~g} / \mathrm{L}$ of SNPs. This shows the impact of silica nanoparticle concentration on germination rate. Furthermore, the recent research by Maryam et al. [118] is worth mentioning, where the researchers developed poly-ethyleneimine (PEI) coated MSNs. The particles were loaded with genetic material (pDNA) for an efficient and successful transfection to plant cells via ultrasonic treatment. Figure 5 reflects the genetic adsorption capacity ofPEIMSNs for DNA.

It is very difficult for the plants to survive during the stress conditions like salinity. This can be resolved by encoding the protein with the gene so that the plant develops more tolerance to the critical conditions of salinity. However, this

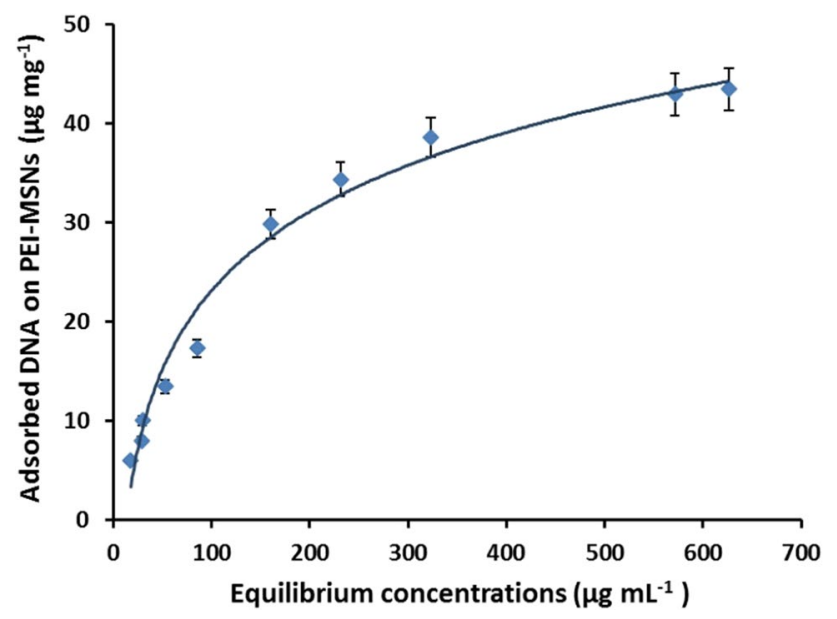

Figure 5 Adsorption Isotherm for pDNA onto PEI-MSNs. Open Access Ref. [118] process is very expensive and time consuming. Hence, the researchers have shown the possibility of loading the gene onto the silica nanoparticles. For example, Kalteh et al. [119] used SNPs on Basil plants with an increased saline conditions. The SNPs were shown to reduce sodium toxicity and enhance the stress tolerance in the plants. On the other hand, another research [120] treated algae (Scenedesmus obliquus) with SNPs. Contrary to the preceding research, it was shown that the higher SNPs concentration reduced the chlorophyl content of the algae. However, good stress tolerance was observed at moderate concentration of SNPs. It can be stated that overall, the use of silica nanoparticles strengthens the plants, enhances their stress tolerance and is non-hazardous Table 2.

\subsection{Applications of SNPs in Food Preservation}

Besides various other applications, the SNPs have also found their contributive role in food preservation. In this, numerous fruits can be coated with silica based hybrid films to increase their shelf life, hence preserve for longer periods of time [127]. This novel approach has been explored and confirmed by various researchers. For example, Mirzadeh et al. [128] synthesized a hybrid composite film of chitosan and nano-silica. The film was coated onto the Longan fruits and was shown to significantly enhance their shelf life. Also, the film reduced the weight loss and browning effect of the fruits. Similarly, another research [129] used the same hybrid film coating on Loquat and observed enhanced shelf life, improved enzymatic activity and increased levels of reducing sugars. Figure 6 shows the synthetic scheme of Chitosan/Silica hybrid composite film for Loquat fruit preservation.

Moreover, the simple process to synthesize silica based hybrid films have attracted the focus of researchers world wide and provoked to exploit for more applications. Similarly, the hybrid composites made with silicates and polymers are shown to possess remarkable barrier properties, i.e.

Table 2 Some of the Agricultural Applications of SNPs [61, 75]

\begin{tabular}{|c|c|c|c|}
\hline SNPs Size (nm) & Concentration of SNPs & Applications & References \\
\hline $20-40$ & - & Enhanced seed viability & {$[121]$} \\
\hline 12 & $8 \mathrm{~g} \mathrm{~L}-1$ & Improved germination rate and mean germination time & {$[117]$} \\
\hline 15 & $112.5 \mathrm{ppm}$ & Insecticide & [122] \\
\hline $10-20$ & $-\overline{200 \mathrm{mg} \mathrm{ml}^{1}}$ & $\begin{array}{l}\text { Growth inhibition and decreased chlorophyll content in Scened- } \\
\text { esmus obliquus }\end{array}$ & {$[120]$} \\
\hline $15-30$ & $2 \mathrm{~g} \mathrm{Kg}^{-1}$ & Entomotoxic effect against Sitophilus oryzae & [123] \\
\hline 50 & $155 \mathrm{ppm}$ & Nano-pesticide against Tutaabsoluta & [124] \\
\hline $20-60$ & $2.06 \mathrm{~g} \mathrm{Kg}^{-1}$ & Insecticide against Callosobruchus maculates & [97] \\
\hline 80 & - & Controlled delivery system for water-soluble pesticide & {$[125]$} \\
\hline $70-100$ & - & Controlled release of avermectin & [126] \\
\hline
\end{tabular}




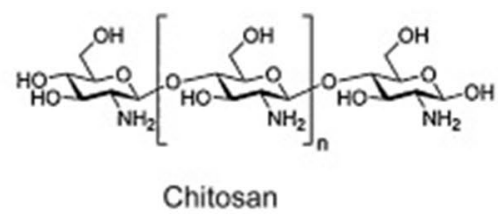

Glacial acetic acid $(0.5 \%, V / V)$
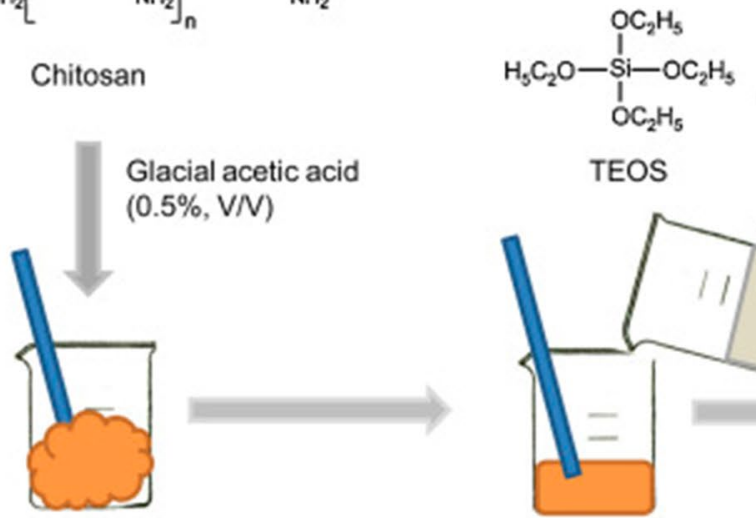

Ethanol $(50 \%, V N)$
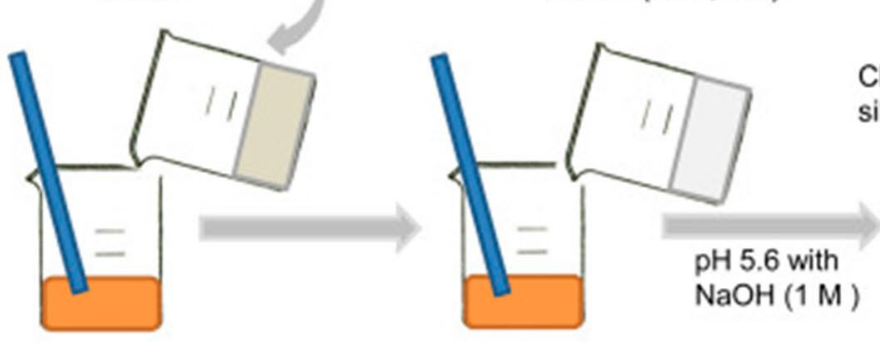

Chitosan/nanosilica hybrid film
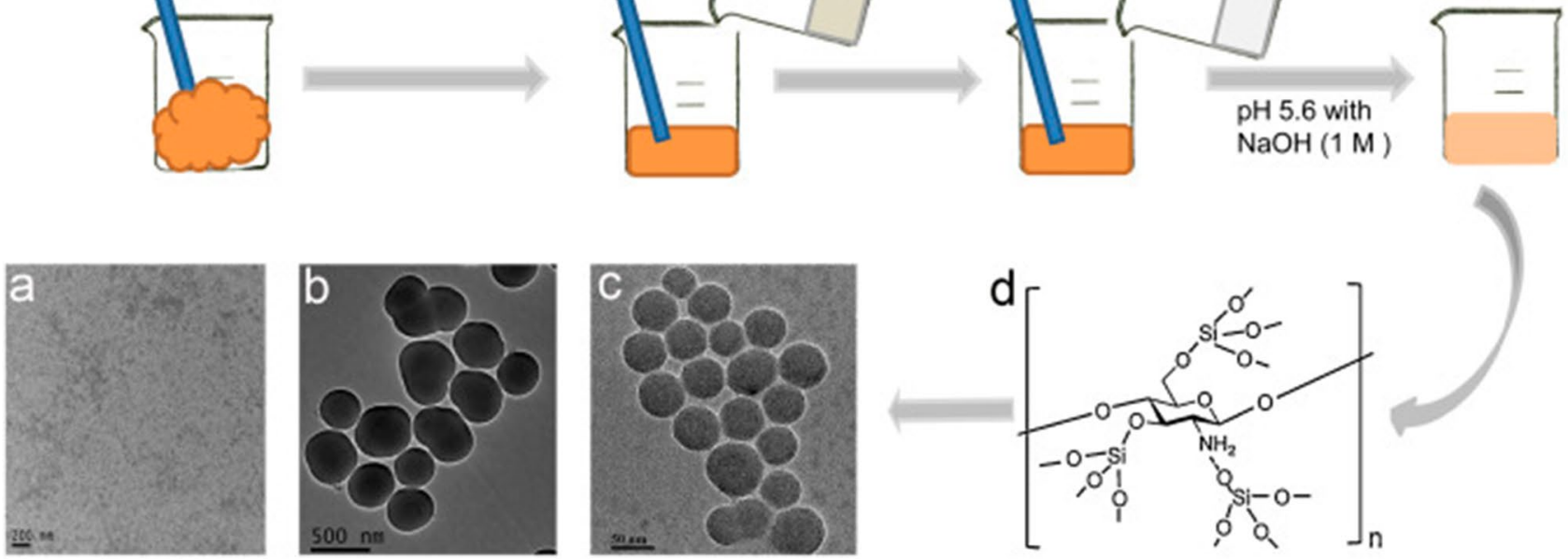

Figure 6 Synthetic scheme for different Chitosan/nano-silica coatings. Reused with permission from ref. [127]

enhancing of diffusive path for an infiltrate molecule [130, 131]. When it comes to packaging materials, the polyethylene bags pose a great threat to the environment, hence SNPs can be combined with biodegradable polymers to synthesize a safer and reliable substitute for packaging material [132-135].

\subsection{Industrial Applications of SNPs}

The mesoporous structure and high surface area of SNPs have made them suitable for various industrial applications. Such applications are on the rise due to the extraordinary properties possessed by these particles. For example, mesoporous silica based nano-fibers have shown great potential for immobilization, hence a suitable material for encapsulation [136]. In this respect, Patel et al. [137] used the MSN fibers to successfully encapsulate Horseradish peroxide (HRP) enzyme without losing its activity. Furthermore, using the same fiber matrix, Takeshi et al. [138] encapsulated capsaicin that resulted in the enzyme to have enhanced stimulus activity. This shows the possibility of successful enzymatic encapsulation using MSNs fibers.

Molecularly imprinted polymers (MIPs) are the synthetic polymers obtained by polymerizing functional monomers and crosslinkers in the presence of template [139]. Besides advantages, these synthetic polymers also contain various downsides such as non-uniform distribution of binding sites and irregular size/shapes. To deal with this, the researchers [140] combined SNPs with MIPs to form a hybrid material. The composite was used to detect rhodamine $\mathrm{B}(\mathrm{RhB})$ dye. SNPs based MIPs system resulted in improved binding, enhanced RhB detection and superior affinity for RhB. In terms of removing methylene blue, the recent studies by Parida et al. [141] and Leshan et al. [64] are worth mentioning. In the first study, researchers developed functionalized MSNs via one-pot synthesis scheme using phosphate based nonsilane precursor. The developed particles consisted 3 types based on $\mathrm{NaOH}$ concentration used. The results indicated that the particles involving higher $\mathrm{NaOH}$ concentrations showed higher removal efficiencies (Figure 7) [141]. Similarly, in the second study, rice husk was used as a raw material to synthesize amine modified silica nanoparticles using sol-gel route. Cetyltrimethylammonium bromide (CTAB) was used as a structure directing agent. As per results, the highest removal efficiency of $95 \%$ was shown by MSN-A particles (Figure 8) [64].

Moreover, SNPs were shown to improve mechanical properties of hybrid polymer when combined with epoxy [142]. Similarly, SNPs combined with alumina showed improved anti wear and antifriction properties [143-147]. 

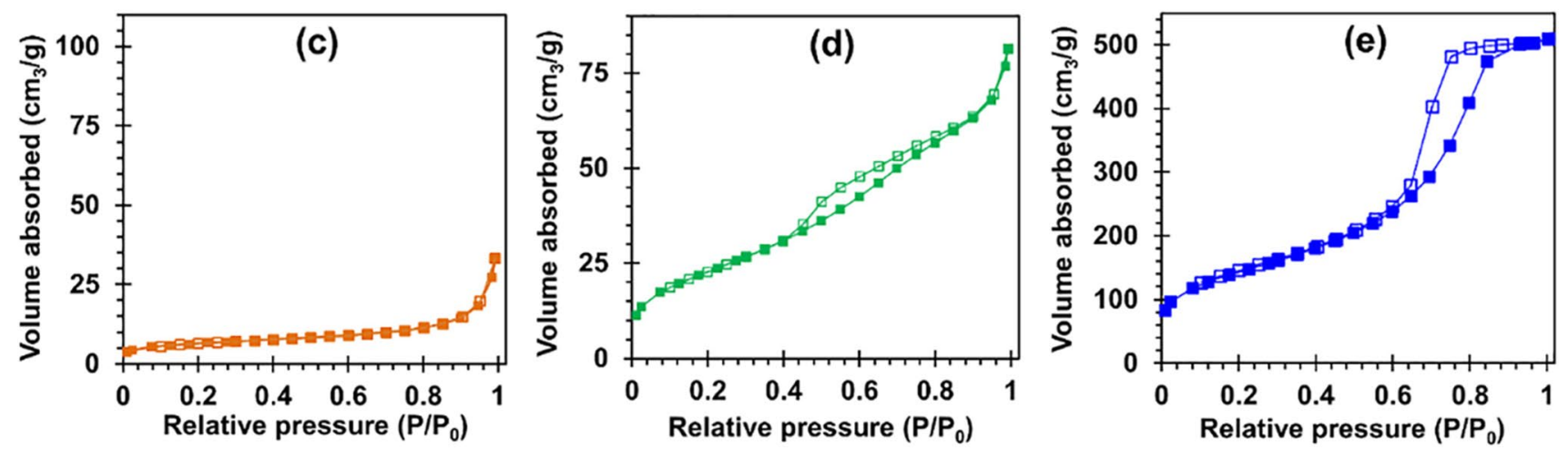

Figure 7 N2 adsorption-desorption isotherm of (c) 0SiO2, (d) $1 \mathrm{SiO} 2$ and (e) 2SiO2. Open Access Ref. [141]

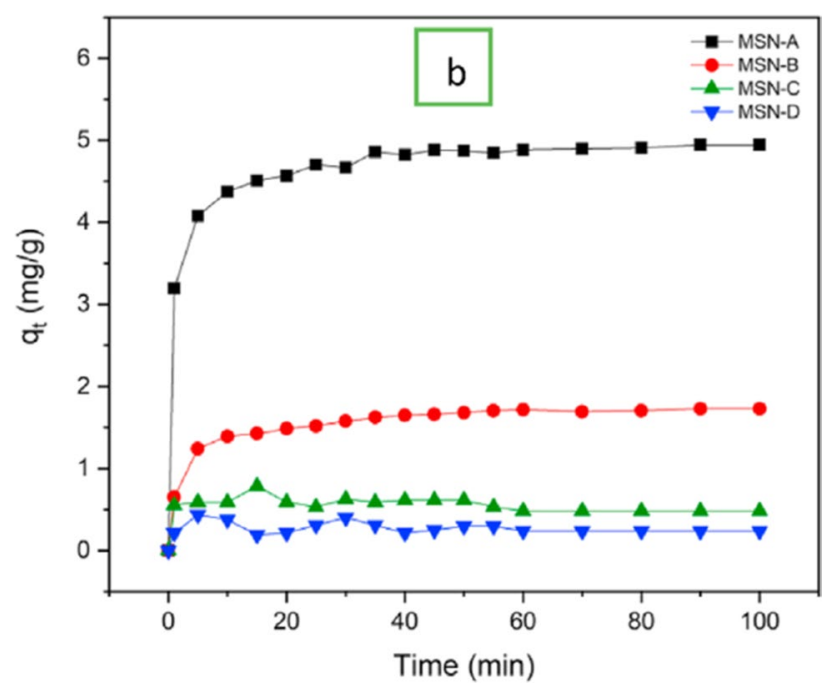

Figure 8 Performance of MSN-A, MSN-B, MSN-C and MSN-D adsorbents on adsorption of MB. Open Access Ref. [64]

Recently, the surface-modified SNPs were developed and successfully applied for oil recovery [148]. Furthermore, Abed and Ali. [149] synthesized environmentally responsive surface-modified SNPs using polyethylene glycol and propyl chains for enhanced oil recovery. Therefore, SNPs are showing promising results as alternatives for chemical surfactants to achieve enhanced oil recovery in oil industries [121].

\subsection{Environmental Applications of SNPs}

Lead contamination in air has become a severe global problem [150]. In this, Yang et al. [151] used electrically charged SNPs exposed to two lead polluted plants to analyze lead adsorption from the atmosphere. The study showed that the SNPs exposed to polluted plants adsorbed more atmospheric lead than without SNPs. Moreover, this was the first study of its kind at the time. One of the recent studies in this direction is by Nashwa et al. [152] where the researchers biosynthesized silica nanoparticles using rice husk. The particles were induced with Trichoderma harzianum MF780864 and used for lead removal from water. Figure 9 shows the adsorption capacity of SNPs.

When it comes to applicability of nanoparticles in environmental remediation, the cost and detailed research are the main barriers. He et al. [153] developed MSNPs (Mesoporous Silica Nanoparticles) with larger pore size and higher surface area. The synthesized nanoparticles were used to successfully remove trace mercury from aqueous solutions. Another study [154] infused MSNPs with cellulose acetate, which was used to remove boron up to $93 \%$. Biocides are the chemical substances that are used to control, destroy, render harmless or exert a controlling effect on any harmful organism [155]. Usually, the accumulation of biocides are avoided via soil uptake, however, this procedure poses hazardous dangers for human health as well as environment. This can be resolved by polymer encapsulation. In this, silica based supports have been used by various researchers. One such study [156] used naturally obtained silica as a carrier for neem extract biocide combined with polycarboxylic acid. The study was able to achieve favorable results. Another study [157] used nano-sized paramagnetic zirconia to selectively remove fluoride from a system with metallic as well as non-metallic pollutants. Moreover, SNPs were used to synthesize stable foam for decontaminating radioactive components from the site. It was also shown that increased hydrophobicity stabilized the foam further.

\subsection{Applications of SNPs in Water Purification}

Silica nanoparticles have already been used by various studies to remove heavy metals from aqueous solutions, which validates their use to purify the wastewater generated by industries [158]. Furthermore, the SNPs have been shown to lower or eradicate the biological oxygen demand. Such an BOD activity is more efficient than the conventional non-SNPs based methods [159]. In this, Park et al. 
Figure 9 Adsorption capacity of Biosynthesized SNPs for $\mathrm{Pb}$ removal. Open Access Ref. [152]

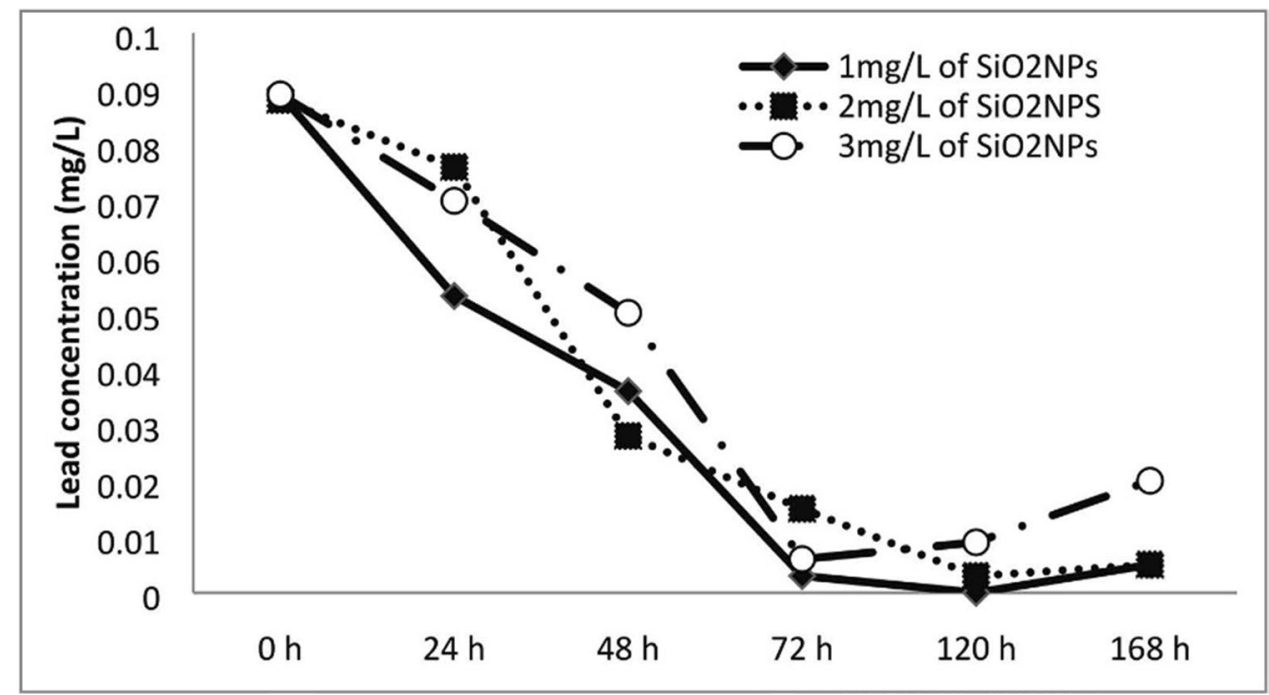

[160] synthesized silver nanoparticles coupled with SNPs to analyze their antimicrobial strength. The study used 2 pathogen viruses; bacteriophage and murine norovirus, in ground, surface, tap and deionized water samples. The coupled silver-silica-nanoparticles (Ag-SNPs) showed higher antiviral strength for murine norovirus than bacteriophage in all 4 types of water samples. Moreover, the antiviral performance of nanoparticles was highly influenced by temperature and organic matter content. The study reveals the possible antiviral use of the silica coupled nanoparticles to kill virus in wastewater. Another study [161] investigated the oil recovery capability of SNPs based film. The researchers used CVD to produce PDMS thin film on SNPs. PDMS being hydrophobic, the film was used to segregate oil from the oil-water mixture. The results were satisfactory and showed the possible use against accidental oil spillage or diffusion that could be detrimental to the environment. Pertaining to oil recovery, another study by Fan et al. [162] synthesized and analyzed the oil recovery factor for polymernanosilica, polymer and water flooding. The oil recovery factor for polymer-nanosilica was shown to be highest with $65 \%$ compared to polymer $55 \%$ and water flooding as $50 \%$ respectively (Figure 10).

Similarly, the dye industries are notorious for the release of harmful chemicals into the water streams. These chemicals can ultimately pose great dangers for aquatic as well as human life. Therefore, the need to treat water before being released is an essential step. In this respect, the study [163] used APTES during SNPs synthesis to increase their pore size. The enhanced pore size SNPs were used to analyze the adsorption capacity for Methylene blue dye and the results were satisfactory. Moreover, the pore size was shown to
Figure 10 Oil Recovery Factor. Open Access Ref. [162]

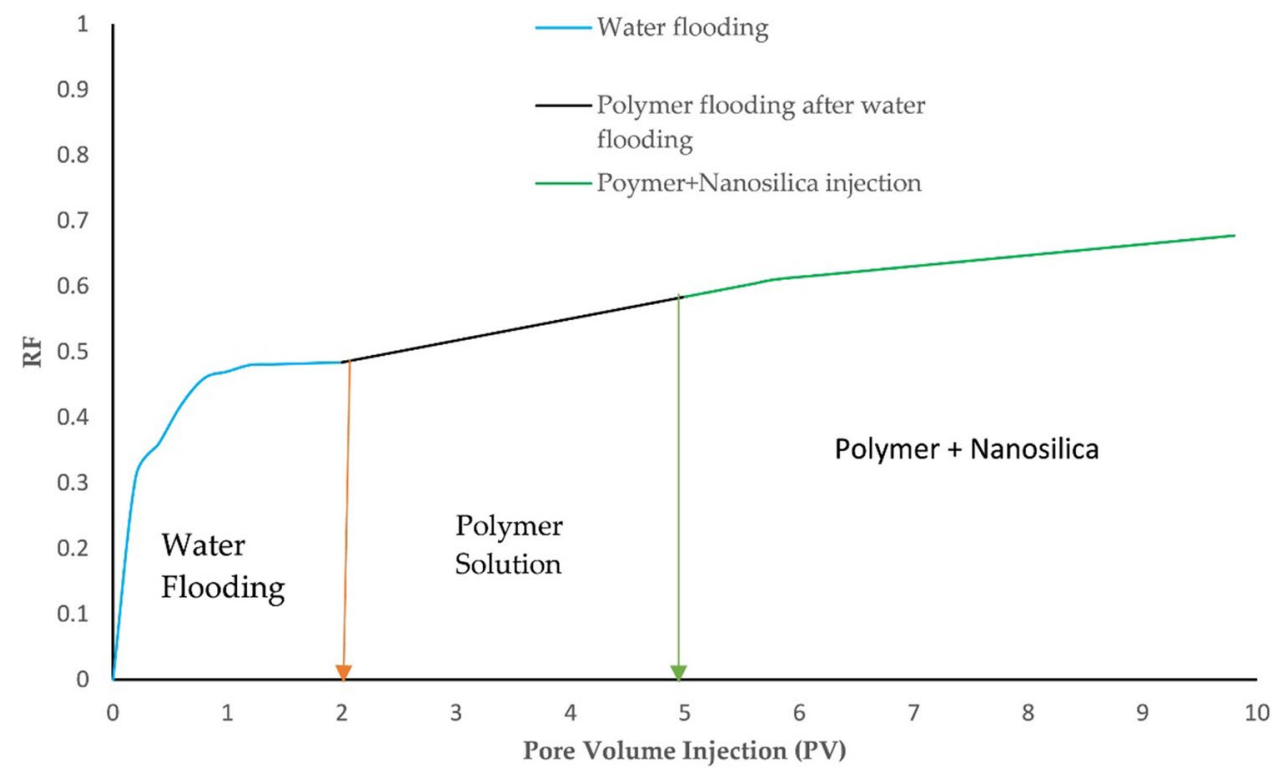


improve the adsorption capacity significantly. Similarly, another type of dye called Methylene red has detrimental consequences for human health if exposed. For example, it can cause skin/eye irritation and digestive disorders. This dye is mostly used by textile and paper industries [164]. To deal with this, the study [165] synthesized SNPs doped with silver and gold particles, which were used against MR dye as an adsorption medium. The results showed satisfactory catalytic degradation by the manufactured particles against MR dye. Furthermore, in terms of aquatic life, the dyes can block the photosynthetic activity of plants and algae [166]. In this respect, the study [167] developed SNPs coupled with $\mathrm{Ag}$ particles as an antifouling adsorbent for effective dye removal and water disinfection. In this respect, few of the most recent works include hybrid SNPs with functionalized mesostructured for methylene blue removal [141] and polysulfone membrane with carbon dots grafted silica for dye removal [168] respectively.

\section{Conclusions and Future Prospects}

Silica nanoparticles (SNPs) have already found a significantly contributive role in nanotechnology. Enriched with remarkable properties like mesoporous structure, high surface area, tunable particle size, pore size and morphology and biocompatibility offer great advantages in multifaceted applications. These nanoparticles have provided highlighting contributions in the fields like agriculture, food preservation, biomedical and catalytic reactions. SNPs are shown to be excellent encapsulation agents for a wide variety of bioactive molecules, which is already safe proven for targeted drug delivery. Moreover, the feasibility of SNPs to merge with different polymeric as well as non-polymeric materials to form hybrid composites has extended the applicable functionalities even further. Mesoporous Silica nanoparticles (MSNPs) have already shown excellent carrier properties, which is applied in targeting specific cancer cell during chemotherapy. Conclusively, it can be stated that SNPs have proven to be safe, functional and reliable substitute and is finding a growing applicability in almost every field. However, based on the investigative review of this remarkable material and its ever growing applications, the authors believe that the following prospects still need to be further exploited and investigated in future research:

1. Further research is needed to exploit more immobilizing agents compatible with MSNs that can be used for catalytic reaction in a single-pot system without influencing mutual reactivity and system environment. Also need to clarify the optimization conditions for such multiimmobilized MSNs species used in catalytic reaction of single-pot system.
2. There is a room for further research to explore the entrapment capabilities of SNPs for colorless and poorly water-soluble drugs for targeted delivery.

3. Need to unveil more seeds like maize seeds that can develop antifungal properties when coupled with SNPs.

4. Need to investigate that in some crops, the SNPs result in an enhanced stress tolerance in saline conditions while in others, it results in chlorophyl reduction.

5. Chitosan/silica hybrid film is shown to increase shelf life of Loquat fruit. In this respect, need to exploit more fruits that can develop higher shelf life when used with the same hybrid film.

6. More enzymes should be explored and investigated for encapsulation onto MSN fibers.

7. Room for exploring more aminosilanes coupled with SNPs as adsorbents for dye removal from wastewater.

\section{Data and Code Availability}

The data in this manuscript is available with the corresponding author and can be provided on reasonable request

Author Contributions Faheem Akhter, Ahsan Atta, Mahmood Nabi: Introduction; Synthesis of SNPs; Faheem Akhter, Shafeeque Ahmed, Mukhtiar Ali, Hafiz Anees-ur-Rehman: Applications of SNPs; Faheem Akhter, Zubair Ahmed: Conclusions and Future Prospects

Code Availability Not Applicable

\section{Declarations}

Conflict of Interest The authors declare no conflict of interest

Ethical Approval Not Applicable

Consent for Publications All the authors of the manuscript mutually agree on submission and publication in the journal

Consent to Participate Not Applicable

\section{References}

1. L X-q ZW (2006) Iron Nanoparticles: The Core-Shell Structure and Unique Properties for Ni(II) Sequestration. Langmuir 22:4638-4642

2. Azat S, Arkhangelsky E, Papathanasiou T et al (2020) Synthesis of Biosourced Silica-Ag Nanocomposites and Amalgamation Reaction with Mercury in Aqueous Solutions. C R Chim 23:77-92. https://doi.org/10.5802/crchim.19

3. L Rodríguez-Sánchez MBML-Q (2000) Electrochemical Synthesis of Silver Nanoparticles. J Phys Chem B 104:9683-9688

4. VK Sharma RYYL (2009) Silver Nanoparticles: Green Synthesis and their Antimicrobial Activities. Adv Colloid Interf Sci 145:83-96 
5. SS Shankar ARAAMS (2005) Controlling the Optical Properties of Lemongrass Extract Synthesized Gold Nanotriangles and Potential Application in Infrared- Absorbing Optical Coatings. Chem Mater 17:566-572

6. Thomas B, Raj MC, Athira BK et al (2018) Nanocellulose, a Versatile Green Platform: From Biosources to Materials and Their Applications. Chem Rev 118:11575-11625

7. Zheng G, He J, Kumar V, et al Discrete metal nanoparticles with plasmonic chirality. pubs.rsc.org

8. Han Q, Chen L, Li W et al (2018) Self-Assembled ThreeDimensional Double Network Graphene Oxide/Polyacrylic Acid Hybrid Aerogel for Removal of $\mathrm{Cu} 2+$ from Aqueous Solution. Environ Sci Pollut Res 25:34438-34447. https://doi. org/10.1007/s11356-018-3409-9

9. Ndolomingo MJ, Bingwa N, Meijboom R (2020) Review of Supported Metal Nanoparticles: Synthesis Methodologies, Advantages and Application as Catalysts. J Mater Sci 55:6195-6241

10. Gao C, Lyu F, Yin Y (2021) Encapsulated Metal Nanoparticles for Catalysis. Chem Rev 121:834-881. https://doi.org/10.1021/ acs.chemrev.0c00237

11. Iriarte-Mesa C, López YC, Matos-Peralta Y et al (2020) Gold, Silver and Iron Oxide Nanoparticles: Synthesis and Bionanoconjugation Strategies Aiming to Electrochemical Applications. Springer, Cham, pp 93-132

12. Ndolomingo MJ, Bingwa N, Meijboom R (2020) Review of supported metal nanoparticles: synthesis methodologies, advantages and application as catalysts. J Mater Sci 55:6195-6241. https:// doi.org/10.1007/s10853-020-04415-x

13. A Ali MHZI ul HAPJAAH (2016) Synthesis, Characterization, Applications, and Challenges of Iron Oxide Nanoparticles. Nanotechnol Sci Appl 9:49-67

14. Goodman BA (2020) Utilization of Waste Straw and Husks from Rice Production: A Review. J Bioresour Bioprod 5:143-162

15. Khan WA, Arain MB, Soylak M (2020) Nanomaterials-Based Solid Phase Extraction and Solid Phase Microextraction for Heavy Metals Food Toxicity. Food ChemToxicol 145https://doi. org/10.1016/j.fct.2020.111704

16. R Narayan UNARSG (2018) Mesoporous Silica Nanoparticles: A Comprehensive Review on Synthesis and Recent Advances. Pharmaceutics 10:118

17. Liou TH, Yang CC (2011) Synthesis and Surface Characteristics of Nanosilica Produced From Alkali-Extracted Rice Husk Ash. Mater Sci Eng B Solid-State Mater Adv Technol 176:521-529. https://doi.org/10.1016/j.mseb.2011.01.007

18. Y Wang QZNHLBJLJLECLHQZTJSW (2015) Mesoporous Silica Nanoparticles in Drug Delivery and Biomedical Applications. Nanomedicine 11:313-327

19. Li Z, Barnes JC, Bosoy A et al (2012) Mesoporous Silica Nanoparticles in Biomedical Applications. Chem Soc Rev 41:25902605. https://doi.org/10.1039/c1cs15246g

20. Isa EDM, Ahmad H, Rahman MBA, Gill MR (2021) Progress in Mesoporous Silica Nanoparticles as Drug Delivery Agents for Cancer Treatment. Pharmaceutics 13:1-33

21. Dayana E, Isa M, Ahmad H, et al (2021) Pharmaceutics Progress in Mesoporous Silica Nanoparticles as Drug Delivery Agents for Cancer Treatment. mdpi.com. https://doi.org/10.3390/pharm aceutics13020152

22. Jeelani PG, Mulay P, Venkat R, Ramalingam C (2020) Multifaceted Application of Silica Nanoparticles. A Review. Silicon 12:1337-1354. https://doi.org/10.1007/s12633-019-00229-y

23. Bera A, Shah S, Shah M et al (2020) Mechanistic Study on Silica Nanoparticles-Assisted Guar Gum Polymer Flooding for Enhanced Oil Recovery in Sandstone Reservoirs. Colloids Surfaces A Physicochem Eng Asp 598:124833. https://doi.org/10. 1016/j.colsurfa.2020.124833
24. Hadia NJ, Ng YH, Stubbs P, Torsaeter O (2021) High Salinity and High Temperature Stable Colloidal Silica Nanoparticles with Wettability Alteration Ability for EOR Applications. mdpi.com. https://doi.org/10.3390/nano11030707

25. Liu S, Han MY (2010) Silica-Coated Metal Nanoparticles. Chem. - An Asian J. 5:36-45

26. A Liberman NMWTAK (2014) Synthesis and Surface Functionalization of Silica Nanoparticles for Nanomedicine. Surf Sci Rep 69:132-158

27. Silva G (2004) Introduction to Nanotechnology and its Applications to Medicine. Surg Neurol 61:216-220

28. Zhao S, Siqueira G, Drdova S et al (2020) Additive Manufacturing of Silica Aerogels. Nature 584:387-392. https://doi.org/ 10.1038/s41586-020-2594-0

29. Le VH, Thuc CNH, Thuc HH (2013) Synthesis of Silica Nanoparticles from Vietnamese Rice Husk by Sol-Gel Method. Nanoscale Res Lett 8:58. https://doi.org/10.1186/ 1556-276x-8-58

30. Sharifnasab H, Alamooti MY (2017) Preparation of Silica Powder from Rice Husk. Agric Eng Int CIGR J 19:158-161

31. Sriwuryandari L, Priantoro EA, Janetasari SA et al (2020) Utilization of Rice Husk (Oryza Sativa) for Amorphous Biosilica (SiO2) Production as a Bacterial Attachment. IOP Conf Ser Earth Environ Sci 483:12023. https://doi.org/10.1088/17551315/483/1/012023

32. Du D, Jiang Y, Feng J, et al (2020) Facile Synthesis of Silica Aerogel Composites via Ambient-Pressure Drying without Surface Modification or Solvent Exchange. Vacuum 173https:// doi.org/10.1016/j.vacuum.2019.109117

33. Guzel Kaya G, Deveci H (2020) Synergistic Effects of Silica Aerogels/Xerogels on Properties of Polymer Composites: A Review. J Ind Eng Chem 89:13-27. https://doi.org/10.1016/j. jiec.2020.05.019

34. Guzel Kaya G, Yilmaz E, Deveci H (2020) Synthesis of Sustainable Silica Xerogels/Aerogels Using Inexpensive Steel Slag and Bean Pod Ash: A Comparison Study. Adv Powder Technol 31:926-936. https://doi.org/10.1016/j.apt.2019.12.013

35. Wong YJ, Zhu L, Teo WS et al (2011) Revisiting the Stöber Method: Inhomogeneity in Silica Shells. J Am Chem Soc 133:11422-11425. https://doi.org/10.1021/ja203316q

36. Xu J, Ren D, Chen N et al (2021) A Facile Cooling Strategy for the Preparation of Silica Nanoparticles with Rough Surface Utilizing a Modified Stöber System. Colloids Surfaces A Physicochem Eng Asp 625:126845. https://doi.org/10.1016/j. colsurfa.2021.126845

37. Prajapati JP, Das D, Katlakunta S et al (2021) Synthesis and Characterization of Ultrasmall Cu2O Nanoparticles on Silica Nanoparticles Surface. Inorganica Chim Acta 515:120069. https://doi.org/10.1016/j.ica.2020.120069

38. P Mohanpuria NRSY (2008) Biosynthesis of Nanoparticles: Technological Concepts and Future Applications. J Nanopart Res 10:507-517

39. V Bansal DRABKAASAAMS (2005) Fungus-Mediated Biosynthesis of Silica and Titania Particles. J Mater Chem 15:2583-2589

40. JN Cha GSDMTD (2000) Biomimetic Synthesis of Ordered Silica Structures Mediated by Block Copolypeptides. Nature 403:289-292

41. Nguyen H, JamaliMoghadam M, Moayedi H (2019) Agricultural Wastes Preparation, Management, and Applications in Civil Engineering: A Review. J Mater Cycles Waste Manag 21:1039-1051. https://doi.org/10.1007/s10163-019-00872-y

42. Zou Y, Yang T (2019) Rice husk, rice husk ash and their applications. In: Rice Bran and Rice Bran Oil: Chemistry, Processing and Utilization. Elsevier, pp 207-246 
43. Pandey LM (2021) Surface Engineering of Nano-Sorbents for the Removal of Heavy Metals: Interfacial Aspects. J Environ Chem Eng 9https://doi.org/10.1016/j.jece.2020.104586

44. Akhter F, Soomro SA, Jamali AR et al (2021) Rice husk ash as green and sustainable biomass waste for construction and renewable energy applications: a review. Biomass Convers Biorefinery. https://doi.org/10.1007/s13399-021-01527-5

45. Nguyen TH, Mai NT, Reddy VRM et al (2020) Synthesis of Silica Aerogel Particles and its Application to Thermal Insulation Paint. Korean J Chem Eng 37:1803-1809. https://doi.org/ 10.1007/s11814-020-0574-6

46. Akhter F, Soomro SA, Inglezakis VJ (2021) Silica Aerogels; A Review of Synthesis, Applications and Fabrication of Hybrid Composites. J Porous Mater. https://doi.org/10.1007/ s10934-021-01091-3

47. Nayak PP, Datta AK (2021) Synthesis of SiO2-Nanoparticles from Rice Husk Ash and its Comparison with Commercial Amorphous Silica through Material Characterization. Silicon 13:1209-1214. https://doi.org/10.1007/s12633-020-00509-y

48. Kamari S, Ghorbani F (2020) Extraction of highly Pure Silica from Rice Husk as an Agricultural by-Product and its Application in the Production of Magnetic Mesoporous Silica MCM41. Biomass Convers Biorefinery. https://doi.org/10.1007/ s13399-020-00637-w

49. Bakar RA, Yahya R, Gan SN (2016) Production of High Purity Amorphous Silica from Rice Husk. Procedia Chem 19:189195. https://doi.org/10.1016/j.proche.2016.03.092

50. Prasad R, Pandey M (2012) Rice Husk Ash as a Renewable Source for the Production of Value added Silica Gel and its Application: An Overview. Bull Chem React Eng Catal 7:1-25. https://doi.org/10.9767/bcrec.7.1.1216.1-25

51. Larbi KK (2010) Synthesis of High Purity Silicon from Rice Husks. Kingsley 128

52. Choudhary R, Venkatraman SK, Bulygina I, et al. (2021) Biomineralization, Dissolution and Cellular Studies of Silicate Bioceramics prepared from Eggshell and Rice Husk. Mater Sci Eng C 118https://doi.org/10.1016/j.msec.2020.111456

53. Nassar MY, Ahmed IS, Raya MA (2019) A Facile and Tunable approach for Synthesis of Pure Silica Nanostructures from Rice Husk for the Removal of Ciprofloxacin Drug from Polluted Aqueous Solutions. J Mol Liq 282:251-263. https://doi.org/ 10.1016/j.molliq.2019.03.017

54. Santana Costa JA, Paranhos CM (2018) Systematic Evaluation of Amorphous Silica Production from Rice Husk Ashes. J Clean Prod 192:688-697. https://doi.org/10.1016/j.jclepro. 2018.05.028

55. Kwan WH, Wong YS (2020) Acid leached Rice Husk Ash (ARHA) in Concrete: A Review. Mater Sci Energy Technol 3:501-507. https://doi.org/10.1016/j.mset.2020.05.001

56. W Weining CJFXHALZSL (2012) Silica Nanoparticles and Framewoks from Rice Husk Biomass. Appl Mater Interfaces 4:977-981

57. Su Y, Liu L, Zhang S, et al. (2020) A Green route for Pyrolysis Poly-Generation of Typical high Ash Biomass, Rice Husk: Effects on Simultaneous Production of Carbonic Oxide-Rich Syngas, Phenol-Abundant Bio-Oil, High-Adsorption Porous Carbon and Amorphous Silicon Dioxide. BioresourTechnol 295https://doi.org/10.1016/j.biortech.2019.122243

58. Saadah N, Zainal B (2020) Characterization of Amorphous Silica and Crystalline Silica From Rice Husk Ash on Water Filtration Application

59. Selvaranjan K, Gamage JCPH, De Silva GIP, Attanayaka V (2020) Thermal Performance of Rice Husk Ash mixed Mortar in Concrete and Masonry Buildings. Bud Archit 19:043-052. https://doi.org/10.35784/bud-arch.2121
60. Askaruly K, Azat S, Sartova Z et al (2020) Obtaining and Characterization of Amorphous Silica from Rice Husk. J Chem Technol Metall 55:88-97

61. Karande SD, Jadhav SA, Garud HB et al (2021) Green and Sustainable Synthesis of Silica Nanoparticles. Nanotechnol Environ Eng 6:29. https://doi.org/10.1007/s41204-021-00124-1

62. San NO, Kurşungöz C, Tümtaş Y et al (2014) Novel One-Step Synthesis of Silica Nanoparticles from Sugarbeet Bagasse by Laser Ablation and their Effects on the Growth of Freshwater Algae Culture. Particuology 17:29-35. https://doi.org/10.1016/j. partic.2013.11.003

63. Alsmaeil AW, Hammami MA, Enotiadis A et al (2021) Encapsulation of an Anionic Surfactant into Hollow Spherical Nanosized Capsules: Size Control, Slow Release, and Potential Use for Enhanced Oil Recovery Applications and Environmental Remediation. ACS Omega 6:5689-5697. https://doi.org/10.1021/ acsomega.0c06094

64. Usgodaarachchi L, Thambiliyagodage C, Wijesekera R, Bakker MG (2021) Synthesis of Mesoporous Silica Nanoparticles Derived from Rice Husk and Surface-Controlled Amine Functionalization for Efficient Adsorption of Methylene Blue from Aqueous Solution. Curr Res Green Sustain Chem 4:100116. https://doi.org/10.1016/j.crgsc.2021.100116

65. Aloulou W, Aloulou H, Khemakhem M, et al (2020) Synthesis and Characterization of Clay-Based Ultrafiltration Membranes supported on Natural Zeolite for Removal of heavy Metals from Wastewater. Environ Technol Innov 18https://doi.org/10.1016/j. eti.2020.100794

66. Shah M (2015) Green Synthesis of Metallic Nanoparticles via Biological Entities. Materials (Basel) 8:7278-7308

67. SR Zhai CHDWYS (2007) Hydrothermal Synthesis of Mesostructured Aluminosilicate Nanoparticles Assisted by Binary Surfactants and Finely Controlled Assembly Process. J NonCryst Solids 353:1606-1611

68. W Zhao JGLZHCJS (2005) Fabrication of Uniform Magnetic Nanocomposite Spheres with a Magnetic Core/Mesoporous Silica Shell Structure. J Am Chem Soc 127:8916-8917

69. Y Huang BTHCVL (2008) One-Pot reaction Cascades Catalyzed by Base-and Acid-Functionalized Mesoporous Silica Nanoparticles. New J Chem 32:1311-1313

70. Shironita S, Mori K, Shimizu T, et al (2008) Preparation of Nano-Sized Platinum Metal Catalyst using Photo-Assisted Deposition Method on Mesoporous Silica including Single-Site Photocatalyst. Appl Surf Sci 254:7604-7607https://doi.org/10. 1016/j.apsusc.2008.01.120

71. Montalvo-Quirós S, Gómez-Graña S, Vallet-Regí M et al (2021) Mesoporous Silica Nanoparticles containing Silver as Novel Antimycobacterial Agents against Mycobacterium Tuberculosis. Colloids Surfaces B Biointerfaces 197:111405. https://doi.org/ 10.1016/j.colsurfb.2020.111405

72. Videira-Quintela D, Guillén F, Montalvo G, Martin O (2020) Silver, Copper, and Copper Hydroxy Salt Decorated Fumed Silica Hybrid Composites as Antibacterial Agents. Colloids Surfaces B Biointerfaces 195:111216. https://doi.org/10.1016/j.colsurfb. 2020.111216

73 Radu CLJWMPVL (2004) Gatekeeping Layer Effect: A Poly (Lactic Acid)-Coated Mesoporous Silica Nanosphere-Based Fluorescence Probe for Detection of Amino-Containing Neurotransmitters. J Am Chem Soc 126:1640-1641

74. Maurel M, Montheil T, Martin J et al (2021) Design of Pegylated Three Ligands Silica Nanoparticles for Multi-Receptor Targeting. Nanomaterials 11:1-23. https://doi.org/10.3390/nano110101 77

75. Zaharudin NS, Mohamed Isa ED, Ahmad H et al (2020) Functionalized Mesoporous Silica Nanoparticles Templated by Pyridinium Ionic Liquid for Hydrophilic and Hydrophobic Drug 
Release Application. J Saudi Chem Soc 24:289-302. https://doi. org/10.1016/j.jscs.2020.01.003

76. Manzano M, Vallet-Regí M (2020) Mesoporous Silica Nanoparticles for Drug Delivery. Adv Funct Mater 30:1902634. https:// doi.org/10.1002/adfm.201902634

77. HA Ab Wab KRNZ (2014) Properties of Amorphous Silica Nanoparticles Colloid Drug Delivery System Synthesized using the Micelle Formation Method. J Nanopart Res 16:2256

78. II Slowing BTSGVL (2007) Mesoporous Silica Nanoparticles for Drug Delivery and Biosensing Applications. Adv Funct Mater 17:1225-1236

79. Dhinasekaran D, Raj R, Rajendran AR et al (2020) Chitosan Mediated 5-Fluorouracil Functionalized Silica Nanoparticle from Rice Husk for Anticancer Activity. Int J Biol Macromol 156:969-980. https://doi.org/10.1016/j.ijbiomac.2020.04.098

80. W Aughenbaugh SRPD (2001) Silica Sol-Gel for the Controlled Release of Antibiotics. II The Effect of Synthesis Parameters on the In Vitro release Kinetics of Vancomycin. J Biomed Mater Res B Part A 57:321-326

81. Y Zhang JWXBTJQZSW (2012) Mesoporous Silica Nanoparticles for increasing the Oral Bioavailability and Permeation of poorly Water Soluble Drugs. Mol Pharm 9:505-513

82. Mashayekhi S, Rasoulpoor S, Shabani S et al (2020) CurcuminLoaded Mesoporous Silica Nanoparticles/Nanofiber Composites for Supporting Long-Term Proliferation and Stemness Preservation of Adipose-Derived Stem Cells. Int J Pharm 587:119656. https://doi.org/10.1016/j.ijpharm.2020.119656

83. Elbialy NS, Aboushoushah SF, Sofi BF, Noorwali A (2020) Multifunctional Curcumin-Loaded Mesoporous Silica Nanoparticles for Cancer Chemoprevention and Therapy. Microporous Mesoporous Mater 291:109540. https://doi.org/10.1016/j.micro meso.2019.06.002

84. Lien Y, research TW materials, (2008) undefined The application of thermosensitive magnetic nanoparticles in drug delivery. Trans Tech Publ. https://doi.org/10.4028/www.scientific.net/ AMR.47-50.528

85. Hu K, Yang Z, Zhang L, et al (2020) Boron agents for neutron capture therapy. Coord Chem Rev 405. https://doi.org/10.1016/j. ccr.2019.213139

86. Wang Y, Xu Y, Yang J, et al. Carborane based Mesoporous Nanoparticles as a Potential Agent for BNCT. pubs.rsc.org

87. Tamanoi F, Matsumoto K, Doan TLH et al (2020) Convergence of the Study on Monochromatic X-rays and the Research on Nanoparticles Opens Up a Possibility to Develop a New Type of Radiation Therapy. Preprints. https://doi.org/10.20944/prepr ints202003.0391.v1

88. Tamanoi F, Chinnathambi S, Laird M et al (2021) Construction of Boronophenylalanine-Loaded Biodegradable Periodic Mesoporous Organosilica Nanoparticles for BNCT Cancer Therapy. Int J Mol Sci Artic. https://doi.org/10.3390/ijms22052251

89. Vares G, Jallet V, Matsumoto Y et al (2020) Functionalized mesoporous silica nanoparticles for innovative boron-neutron capture therapy of resistant cancers. Nanomedicine Nanotechnology, Biol Med 27. https://doi.org/10.1016/j.nano.2020.102195

90. Fanizza E, Zhao H, De Zio S, et al Encapsulation of Dual Emitting Giant Quantum Dots in Silica Nanoparticles for Optical Ratiometric Temperature Nanosensors. mdpi.com. https://doi. org/10.3390/app10082767

91. Xie H, Chen E, Ye Y, et al. Highly Stabilized Gradient Alloy Quantum Dots and Silica Hybrid Nanospheres by Core Double Shells for Photoluminescence Devices. ACS Publ

92. Reis S Dos, Pinto S, ... F de M-P (2020) undefined Discrepancy on Tissue Deposition of Graphene Quantum Dots, Polycaprolactone Nanoparticle and Magnetic Mesoporous Silica Nanoparticles in Young and .... Springer
93. Ha CV, Tuan CA, Thi N et al (2020) Synthesis and Optical Characterizations of the Fluorescence Silica Nanoparticles Containing Quantum Dots. VNU J Sci Math 36:87-97. https://doi.org/10. 25073/2588-1124/vnumap.4476

94. Lin X, Kong M, Wu N et al (2020) Measurement of Temperature Distribution at the Nanoscale with Luminescent Probes Based on Lanthanide Nanoparticles and Quantum Dots. ACS Appl Mater Interfaces 12:52393-52401. https://doi.org/10.1021/acsami. 0c15697

95. V Mamaeva CSML (2013) Mesoporous Silica Nanoparticles in Medicine-Recent Advances. Adv Drug Deliv Rev 65:689-702

96. Wen M, Chen M, Chen K et al (2021) Superhydrophobic composite graphene oxide membrane coated with fluorinated silica nanoparticles for hydrogen isotopic water separation in membrane distillation. J Memb Sci 626. https://doi.org/10.1016/j. memsci.2021.119136

97. Su S, Chen L, Hao L et al (2021) Fluorinated Sodium Carboxymethyl Cellulose Nanoparticles as Carrier for Improving Adhesion and Sustaining Release of AVM. Taylor Fr 58:219-231. https:// doi.org/10.1080/10601325.2020.1840922

98. Guo C, Ding H, Xie M et al (2021) Multifunctional superamphiphobic fluorinated silica with a core-shell structure for antifouling and anti-corrosion applications. Colloids Surfaces A Physicochem Eng Asp 615. https://doi.org/10.1016/j.colsurfa. 2021.126155

99. Wen S, Wang P, Wang L (2021) Preparation and antifouling performance evaluation of fluorine-containing amphiphilic silica nanoparticles. Colloids Surfaces A Physicochem Eng Asp 611. https://doi.org/10.1016/j.colsurfa.2020.125823

100. Gupta S, Martoïa F, Orgéas L, Dumont PJJ (2018) Ice-templated porous nanocellulose-based materials: Current progress and opportunities for materials engineering. Appl Sci 8

101. L Zhang FGJCAWRLOF (2008) Nanoparticles in Medicine: Therapeutic Applications and Developments. Clin Pharmacol Ther 83:761-769

102. A Maleki HKASJRVAMH (2017) Mesoporous Silica Materials: From Physico-Chemical Properties to Enhanced Dissolution of Poorly Water-Soluble Drugs. J Control Release 262:329-347

103. Mozafarinia M, Karimi S, Materials MF-... M, 2021 undefined targeting using Trastuzumab-conjugated mesoporous silica nanoparticles: Towards the new strategy for decreasing size and high drug loading capacity for drug .... Elsevier

104. Zhang R, Wang X, Fan N, Li J (2021) Enhanced anticancer performances of doxorubicin loaded macro-mesoporous silica nanoparticles with host-metal-guest structure. Microporous Mesoporous Mater 310. https://doi.org/10.1016/j.micromeso. 2020.110589

105. Day CM, Sweetman MJ, Hickey SM, et al (2021) molecules Concept Design, Development and Preliminary Physical and Chemical Characterization of Tamoxifen-Guided-Mesoporous Silica Nanoparticles. mdpi.com. https://doi.org/10.3390/molec ules 26

106. Liu M, Liu J, Wang Y et al (2021) Redox-responsive mesoporous silica nanoparticles based on fluorescence resonance energy transfer for anti-cancer drug targeting and real-time monitoring. J Mater Res. https://doi.org/10.1557/s43578-021-00252-z

107. Guo L, Ping J, Qin J, et al (2021) A Comprehensive Study of Drug Loading in Hollow Mesoporous Silica Nanoparticles: Impacting Factors and Loading Efficiency. mdpi.com. https:// doi.org/10.3390/nano11051293

108. Akbarzadeh M, Babaei M, Abnous K et al (2019) Hybrid Silica-Coated Gd-Zn-Cu-In-S/Zns Bimodal Quantum Dots as an Epithelial Cell Adhesion Molecule Targeted Drug Delivery and Imaging System. Int J Pharm 570:118645. https://doi.org/10. 1016/j.ijpharm.2019.118645 
109. Sharma SK, Sharma AR, Pamidimarri SDVN, et al (2019) Bacterial Compatibility/Toxicity of Biogenic Silica (B-SiO2) Nanoparticles Synthesized From Biomass Rice Husk Ash. Nanomaterials 9https://doi.org/10.3390/nano9101440

110. Zaman A, Huang F, Jiang M, et al (2020) Preparation, Properties, and Applications of Natural Cellulosic Aerogels: A Review. In: Energy Built Environ. https://www.sciencedirect.com/science/ article/pii/S2666123319300066. Accessed 8 Jul 2020

111. EJ Kwon MSABGBFRER (2017) Porous Silicon Nanoparticle Delivery of Tandem Peptide Anti-Infectives for the Treatment of Pseudomonas Aeruginosa Lung Infections.Adv Mater 29:1701527

112. S Valetti XXJC-GPBMB-CMAAF (2017) Clofazimine Encapsulation in Nanoporous Silica Particles for the Oral Treatment of Antibiotic-Resistant Mycobacterium Tuberculosis Infections. Nanomedicine 12:831-844

113. Jatoi AS, Hashmi Z, Adriyani R et al (2021) Recent Trends and Future Challenges of Pesticide Removal Techniques - A Comprehensive Review. J Environ Chem Eng 9:105571. https://doi. org/10.1016/j.jece.2021.105571

114. El-Shetehy M, Moradi A, Maceroni M et al (2021) Silica Nanoparticles Enhance Disease Resistance in Arabidopsis Plants. Nat Nanotechnol 16:344-353. https://doi.org/10.1038/ s41565-020-00812-0

115. Pereira ADES, Oliveira HC, Fraceto LF, Santaella C (2021) Nanotechnology Potential in Seed Priming for Sustainable Agriculture. Nanomaterials 11:1-29

116. F Torney BTVLKW (2007) Mesoporous Silica Nanoparticles Deliver DNA and Chemicals Into Plants. Nat Nanotechnol 2:295-300

117. MH Siddiqui MA-W (2014) Role of nano-SiO 2 in Germination of Tomato (Lycopersicum esculentum seeds mill.). Saudi J Biol Sci 21:13-17

118. Zolghadrnasab M, Mousavi A, Farmany A, Arpanaei A (2021) Ultrasound-Mediated Gene Delivery Into Suspended Plant Cells Using Polyethyleneimine-Coated Mesoporous Silica Nanoparticles. Ultrason Sonochem 73:105507. https://doi.org/10.1016/j. ultsonch.2021.105507

119. Kalteh M, Taj Alipour Z, Ashraf S et al (2014) Effect of silica Nanoparticles on Basil (Ocimum basili-cum) Under Salinity Stress. Islamic Azad University, Damghan Branch, Islamic Republic of Iran

120. C Wei YZJGBHXYJY (2010) Effects of Silica Nanoparticles on Growth and Photosynthetic Pigment Contents of Scenedesmus obliquus. J Environ Sci 22:155-160

121 R Suriyaprabha GKRYPPVRNK (2012) Growth and Physiological Responses of Maize (Zea mays L.) to Porous Silica Nanoparticles in Soil. J Nanopart Res 14:1294

122. TK Barik RKAG (2012) Silica Nanoparticle: A Potential New Insecticide for Mosquito Vector Control. Parasitol Res 111:1075-1083

123. N Debnath SDDSRCSBAG (2011) Entomotoxic Effect of Silica Nanoparticles Against Sitophilus Oryzae (L.). J Pest Sci 84:99-105

124. S Magda MH (2016) Determinations of the Effect of Using Silca Gel and Nano-Silica Gel Against TutaAbsoluta (Lepidoptera: Gelechiidae) in Tomato Fields. J Chem Pharm Res 8:506-512

125. F Liu LWZLWYHSJC (2006) Porous Hollow Silica Nanoparticles as Controlled Delivery System for Water-Soluble Pesticide. Mater Res Bull 41:2268-2275

126. LX Wen ZLHZALJC (2005) Controlled Release of Avermectin from Porous Hollow Silica Nanoparticles. Pest Manag Sci Former Pestic Sci 61:583-590

127. H Song WYPJWWXWLYYZ (2016) Effects of Chitosan/NanoSilica on Postharvest Quality and Antioxidant Capacity of Loquat Fruit during Cold Storage. Postharvest Biol Technol 119:41-48
128. A Mirzadeh MK (2007) The Effect of Composition and DrawDown Ratio on Morphology and Oxygen Permeability of Polypropylene Nanocomposite Blown Films. Eur Polym J 43:3757-3765

129. Azeredo H (2009) Nanocomposites for food packaging applications. Food Res Int 42:1240-1253

130. MF Fakoya SS (2017) Emergence of Nanotechnology in the Oil and Gas Industry: Emphasis on the Application of Silica Nanoparticles. Petroleum 3:391-405

131. SJD Sofla LJYZ (2018) Insight Into the Stability of Hydrophilic Silica Nanoparticles in Seawater for Enhanced Oil Recovery Implications. Fuel 216:559-571

132. Hernández-García E, Vargas M, González-Martínez C, Chiralt A (2021) Biodegradable Antimicrobial Films for Food Packaging: Effect of Antimicrobials on Degradation. mdpi.com. https://doi.org/10.3390/foods

133. Omerović N, Djisalov M, Živojević K et al (2021) Comprehensive Reviews in Food Science and Food Safety Antimicrobial Nanoparticles and Biodegradable Polymer Composites for Active Food Packaging Applications. Wiley Online Libr 20:2428-2454. https://doi.org/10.1111/1541-4337.12727

134. Wu F, Misra M, Mohanty AK (2021) Challenges and new opportunities on barrier performance of biodegradable polymers for sustainable packaging. Prog Polym Sci 117. https:// doi.org/10.1016/j.progpolymsci.2021.101395

135. Lu W, Cui R, Zhu B et al (2021) Influence of clove essential oil immobilized in mesoporous silica nanoparticles on the functional properties of poly(lactic acid) biocomposite food packaging film. J Mater Res Technol 11:1152-1161. https:// doi.org/10.1016/j.jmrt.2021.01.098

136. Miri S, Raghuwanshi VS, Andrews PC, Batchelor W (2021) Composites of Mesoporous Silica Precipitated on Nanofibrillated Cellulose and Microfibrillated Cellulose: Effect of Fibre Diameter and Reaction Conditions on Particle Size and Mesopore Diameter. Microporous Mesoporous Mater 311https://doi.org/10.1016/j.micromeso.2020.110701

137. AC Patel SLJYYW (2006) In Situ Encapsulation of Horseradish Peroxidase in Electro Spun Porous Silica Fibers for Potential Biosensor Applications. Nano Lett 6:1042-1046

138. Yamauchi T, Saitoh T, Shirai K et al (2010) Immobilization of Capsaicin onto Silica Nanoparticle Surface and Stimulus Properties of the Capsaicin-Immobilized Silica. J Polym Sci Part A Polym Chem 48:1800-1805. https://doi.org/10.1002/ pola.23948

139. Piletsky S, Canfarotta F, Poma A et al (2020) Molecularly Imprinted Polymers for Cell Recognition. Trends Biotechnol. 38:368-387

140. Long Z, Xu W, Lu Y, Qiu H (2016) Nanosilica-based molecularly imprinted polymer nanoshell for specific recognition and determination of rhodamine $\mathrm{B}$ in red wine and beverages. J Chromatogr B Anal Technol Biomed Life Sci 1029-1030:230-238. https://doi.org/10.1016/j.jchromb.2016.06.030

141. Parida D, Salmeia KA, Sadeghpour A et al (2021) TemplateFree Synthesis of Hybrid Silica Nanoparticle with Functionalized Mesostructure for Efficient Methylene Blue Removal. Mater Des 201:109494. https://doi.org/10.1016/j.matdes.2021.109494

142. Karnati SR, Agbo P, Zhang L (2020) Applications of Silica Nanoparticles in Glass/Carbon Fiber-Reinforced Epoxy Nanocomposite. Compos. Commun. 17:32-41

143. Wei J, He C, Fan C et al (2021) Comparison in the effects of alumina, ceria and silica nanoparticle additives on the combustion and emission characteristics of a modern methanol-diesel dual-fuel CI engine. Energy Convers Manag 238. https://doi.org/ 10.1016/j.enconman.2021.114121

144. Zhao Y, Wang L, Kochubei A et al (2021) Formation and Location of Pt Single Sites Induced by Pentacoordinated Al Species 
on Amorphous Silica-Alumina. J Phys Chem Lett 12:2536-2546. https://doi.org/10.1021/acs.jpclett.1c00139

145. Wu Y, Shang L, Pan Z et al (2021) Gas hydrate formation in the presence of mixed surfactants and alumina nanoparticles. J Nat Gas Sci Eng 94. https://doi.org/10.1016/j.jngse.2021.104049

146. Dhatarwal P, Choudhary S, Sengwa RJ (2021) Dielectric and optical properties of alumina and silica nanoparticles dispersed poly(methyl methacrylate) matrix-based nanocomposites for advanced polymer technologies. J Polym Res 28. https://doi.org/ 10.1007/s10965-020-02406-9

147. Balogun S, Yaro S, ... MA-FJO (2021) undefined Production and Characterization of Alumina Nanoparticles from Giro Clay Via Acid Leaching With Sol Gel Method. futajeet.com. https://doi. org/10.51459/futajeet.2021.15.1.261

148. Olayiwola SO, Dejam M (2021) Comprehensive experimental study on the effect of silica nanoparticles on the oil recovery during alternating injection with low salinity water and surfactant into carbonate reservoirs. J Mol Liq 325:115178. https://doi.org/ 10.1016/j.molliq.2020.115178

149. Behzadi A, Mohammadi A (2016) Environmentally Responsive Surface-Modified Silica Nanoparticles for Enhanced Oil Recovery. J Nanoparticle Res 18https://doi.org/10.1007/ s11051-016-3580-1

150. Azimi A, Azari A, Rezakazemi M, Ansarpour M (2017) Removal of Heavy Metals from Industrial Wastewaters: A Review. ChemBioEng Rev 4:37-59. https://doi.org/10.1002/cben.201600010

151. Yang X, Shen Z, Zhang B et al (2013) Silica nanoparticles capture atmospheric lead: Implications in the treatment of environmental heavy metal pollution. Chemosphere 90:653-656. https:// doi.org/10.1016/j.chemosphere.2012.09.033

152. El-Gazzar N, Almanaa TN, Reda RM et al (2021) Assessment the Using of Silica Nanoparticles (Sio2nps) Biosynthesized from Rice Husks By Trichoderma Harzianum Mf780864 as Water Lead Adsorbent for Immune Status of Nile Tilapia (Oreochromis Niloticus). Saudi J Biol Sci. https://doi.org/10.1016/j.sjbs.2021. 05.027

153. He C, Ren L, Zhu W et al (2015) Removal of mercury from aqueous solution using mesoporous silica nanoparticles modified with polyamide receptor. J Colloid Interface Sci 458:229-234. https:// doi.org/10.1016/j.jcis.2015.07.054

154. Albertini F, Ribeiro T, Alves S et al (2018) Boron-chelating membranes based in hybrid mesoporous silica nanoparticles for water purification. Mater Des 141:407-413. https://doi.org/10. 1016/j.matdes.2018.01.001

155. Dev Kumar G, Mishra A, Dunn L et al (2020) Biocides and Novel Antimicrobial Agents for the Mitigation of Coronaviruses. Front Microbiol 11:1351

156. Mattos BD, Rojas OJ, Magalhães WLE (2017) Biogenic Silica Nanoparticles Loaded With Neem Bark Extract as Green, SlowRelease Biocide. J Clean Prod 142:4206-4213. https://doi.org/ 10.1016/j.jclepro.2016.11.183

157. Sonn JS, Lee JY, Jo SH et al (2018) Effect of surface modification of silica nanoparticles by silane coupling agent on decontamination foam stability. Ann Nucl Energy 114:11-18. https://doi.org/10.1016/j.anucene.2017.12.007

158. Akhter F, Soomro SA, Siddique M, Ahmed M (2021) Plant and Non-plant based Polymeric Coagulants for Wastewater Treatment: A Review. J Kejuruter 33:175-181. https://doi.org/10. 17576/jkukm-2021-33(2)-02

159. Sibag M, Choi BG, Suh C et al (2015) Inhibition of total oxygen uptake by silica nanoparticles in activated sludge. J Hazard Mater 283:841-846. https://doi.org/10.1016/j.jhazmat.2014.10.032

160. Park SJ, Ko YS, Jung H et al (2018) Disinfection of waterborne viruses using silver nanoparticle-decorated silica hybrid composites in water environments. Sci Total Environ 625:477-485. https://doi.org/10.1016/j.scitotenv.2017.12.318

161. Cho YK, Park EJ, Kim YD (2014) Removal of oil by gelation using hydrophobic silica nanoparticles. J Ind Eng Chem 20:1231-1235. https://doi.org/10.1016/j.jiec.2013.08.005

162. Fan G, Li M, Chen X et al (2021) Polymer-Nanosilica-Assisted to Evaluate Oil Recovery Performances in Sandstone Reservoirs. Energy Reports 7:2588-2593. https://doi.org/10.1016/j.egyr. 2021.04.047

163. Karim AH, Jalil AA, Triwahyono S et al (2012) Amino modified mesostructured silica nanoparticles for efficient adsorption of methylene blue. J Colloid Interface Sci 386:307-314. https:// doi.org/10.1016/j.jcis.2012.07.043

164. Badr Y, Abd El-Wahed MG, Mahmoud MA (2008) Photocatalytic Degradation of Methyl Red dye by silica nanoparticles. J Hazard Mater 154:245-253. https://doi.org/10.1016/j.jhazmat. 2007.10.020

165. Badr Y, El-Wahed MA, materials MM-J of hazardous, (2008) undefined (2008) Photocatalytic degradation of methyl red dye by silica nanoparticles. Elsevier 154:245-253. https://doi.org/10. 1016/j.jhazmat.2007.10.020

166. Chaibakhsh N, Ahmadi N, Zanjanchi MA (2014) Use of Plantago Major L. as a Natural Coagulant for Optimized Decolorization of Ddye-Containing Wastewater. Ind Crops Prod 61:169-175. https://doi.org/10.1016/j.indcrop.2014.06.056

167. Das SK, Khan MMR, Parandhaman T et al (2013) Nano-silica fabricated with silver nanoparticles: Antifouling adsorbent for efficient dye removal, effective water disinfection and biofouling control. Nanoscale 5:5549-5560. https://doi.org/10.1039/c3nr0 $0856 \mathrm{~h}$

168. Heng ZW, Tan YY, Chong WC, et al (2021) Preparation of a novel polysulfone membrane by incorporated with carbon dots grafted silica from rice husk for dye removal. J Water Process Eng 40https://doi.org/10.1016/j.jwpe.2020.101805

Publisher's Note Springer Nature remains neutral with regard to jurisdictional claims in published maps and institutional affiliations. 